\title{
A IMPORTÂNCIA DA PESQUISA CLÍNICA VETERINÁRIA EM BOVINOS DE CORTE E SUA RELAÇÃO COM SAÚDE ÚNICA
}

\author{
Thábata Orbeteli Viotto Santos ${ }^{1}$, Heytor Henrique Garcia Borges ${ }^{2}$ \\ ${ }^{1}$ Graduanda em Medicina Veterinária pela Universidade Metodista de São Paulo, Faculdade \\ da Saúde, Campus Planalto, São Bernardo do Campo - São Paulo, Brasil. E-mail: \\ thabata.orbeteli@hotmail.com \\ ${ }^{2}$ Médico Veterinário Especialista, Docente do curso de Medicina Veterinária, Universidade \\ Metodista de São Paulo, Faculdade da Saúde, Campus Planalto, São Bernardo do Campo - \\ São Paulo, Brasil.
}

Recebido em: 15/12/2021 - Aprovado em: 15/12/2021 - Publicado em: 30/12/2021

DOI: 10.18677/Agrarian_Academy_2021B1

trabalho licenciado sob licença Creative Commons Attribution-NonCommercial-NoDerivatives 4.0 International License.

\begin{abstract}
RESUMO
O atual cenário da resistência antimicrobiana coloca em risco a saúde pública e para evitar a chance de uma crise sanitária, as autoridades de saúde estabelecem medidas de controle à serem realizadas, utilizando o conceito de saúde única (meio ambiente,animais e humanos). O objetivo deste estudo foi descrever a ação da medicina veterinária no controle dos períodos de carência e efeitos residuais de antimicrobianos na proteína animal, com a intenção de minimizar o impacto da resistência aos antibióticos na saúde humana. Através da recomendação de autoridades e guias sanitários internacionais percebe-se a importância dos estudos clínicos supervisionados pelos médicos veterinários na manutenção da saúde pública.
\end{abstract}

PALAVRAS-CHAVE: Resistência Antimicrobiana; Saúde Pública; Testes em animais.

\section{THE IMPORTANCE OF VETERINARY CLINICAL RESEARCH IN BEEF CATTLE AND ITS RELATIONSHIP TO UNIQUE HEALTH: LITERATURE REVIEW}

\begin{abstract}
The current scenario of antimicrobial resistance puts public health at risk and to avoid a chance of a health crisis, as health authorities establish control measures to carry out, using the concept of one health (environment, animals and humans). The aim of the study was to describe the action of veterinary medicine without controlling the withdrawal periods and residual effects of antimicrobials in animal protein, with the intention of minimizing the impact of antibiotic resistance on human health. Through the recommendation of international health authorities and guides, the importance of clinical studies supervised by veterinarians in maintaining public health is perceived.
\end{abstract}

KEYWORDS: Antimicrobial Resistance; Public Health, Animal Testing. 


\section{INTRODUÇÃO}

Atualmente, discute-se muito sobre o conceito de "saúde única", porém apesar de importante, continua abstrato para grande parte da população, a qual, muitas vezes, é incapaz de reconhecer o papel da Medicina Veterinária na manutenção do funcionamento da saúde animal, humana e ambiental (CFMV, 2020).

FIGURA 1 - Tríade do conceito Saúde única

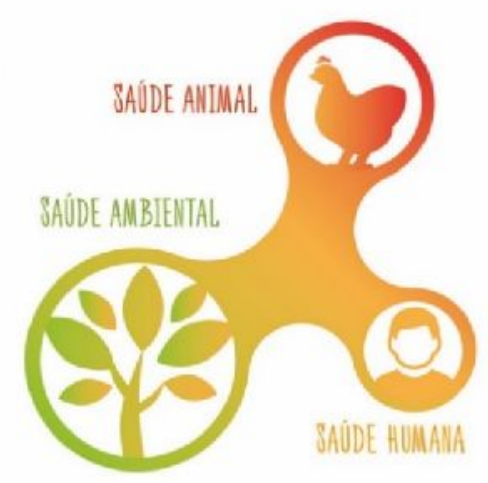

Fonte: CFMV (2020)

É fato que a atuação direta do Médico Veterinário é com os animais. Apesar disso, a profissão existe e funciona em prol dos seres humanos. De modo genérico, é possível extrapolar que as ações diretas da Medicina Veterinária sejam sobre animais silvestres, domésticos e de produção. Através da preservação dos animais silvestres é possível manter o equilíbrio no ecossistema. Atualmente, com o espaço que os animais domésticos têm ocupado dentro das famílias, a presença de um pet saudável, muitas vezes, é essencial à saúde mental de muitos tutores. A atuação da Medicina Veterinária na cadeia produtiva de animais de produção é a de maior impacto na saúde humana, estando presente "do pasto ao prato", ou seja, em todas as etapas do processo de produção (CRMV, 2021).

O mercado consumidor de proteína bovina prevê que a carne seja de qualidade e possui normas e padrões elevados para lhe classificar como tal. Os produtos devem ser diferenciados e exclusivos, além de apresentar excelência de aspectos visuais, nutricionais, seguros e apetitosos (FAO; WHO, 2019a). Para atender a essas demandas, durante a vida do animal, se faz necessário o uso de fármacos para prevenção, tratamento e também com o objetivo de potencializar resultados desse animal. No entanto, alguns desses fármacos, se utilizados de maneira inadequada e sem supervisão, podem ser prejudiciais à saúde humana (GONZALES et al., 2017).

Visando proteger a saúde humana e evitar crises sanitárias, a comercialização e/ou o lançamento de um novo produto veterinário no mercado brasileiro, exige que o mesmo esteja registrado no Ministério da Agricultura, Pecuária e Abastecimento (MAPA), órgão responsável pela fiscalização e liberação desses produtos. A pesquisa clínica veterinária é o método exclusivo, essencial e fundamental para o registro dos novos produtos veterinários perante a legislação brasileira. Os testes destinados a aprovação e registro de fármacos, especificamente, dos antimicrobianos indicados ao gado de corte são imprescindíveis para determinação do período de carência de abate, visando 
garantir a segurança dos alimentos e impedir que o consumo da proteína bovina seja prejudicial à saúde humana (CRMV, 2021).

O objetivo deste trabalho foi expor a conexão entre a medicina veterinária e seu impacto na saúde pública através de uma revisão de literatura. A qual acontece a partir da realização de estudos clínicos em animais vivos para determinação e/ou validação dos períodos de carência dos antibióticos veterinários de relevância na saúde humana, para evitar o efeito residual na proteína bovina (CRMV, 2021).

\section{Saúde Única}

No Brasil, a Medicina Veterinária é considerada uma profissão da área da saúde há 23 anos (BRASIL, 1998). Sua atuação é diversa e têm se mostrado relevante no desenvolvimento econômico e social de um país, através do cuidado com a saúde e bem-estar de animais de companhia e de produção, na produção de alimentos saudáveis e seguros, na manutenção e preservação do equilíbrio do ecossistema, além de zelar pela saúde pública evitando e controlando eventuais colapsos na sociedade (CFMV, 2020).

Segundo a World Organization for Animal Health (2019), cerca de 60\% das infecções em humanos são zoonoses, ou seja, provenientes de animais, sejam eles domésticos ou selvagens. O último estudo da Organização das Nações Unidas (ONU), realizado em 2019, prevê que o consumo de produtos de origem animal tenha um aumento de quase 70\% até 2050 (ONU,2020). Sabe-se que o Brasil é um dos maiores exportadores do mundo de proteína animal, no caso de carne bovina, se mantém em primeiro lugar representando $6 \%$ do PIB brasileiro, o que garante um bom desenvolvimento na economia, entretanto se não houver a fiscalização adequada, a exportação brasileira pode ser responsável por escalonar e facilitar a transmissão de doenças a nível nacional e mundial (EMBRAPA, 2021).

FIGURA 2 - Participação da produção brasileira no mundo - (2019) PARTICIPAC̄ÃO DA PRODUÇ̄̃O BRASILEIRA NO MUNDO - 2019 Enibra

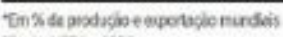
Toricusaheasp:
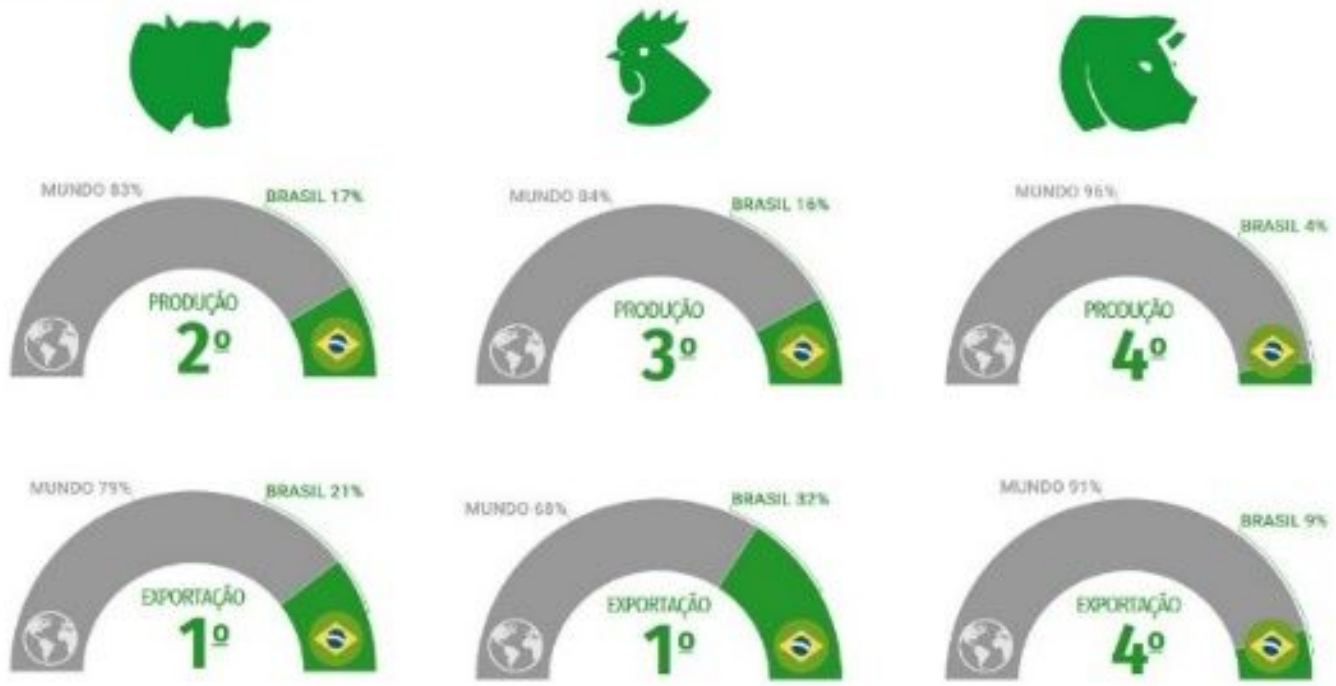

Fonte: EMBRAPA (2019) 
O Médico Veterinário, em suas mais diversas especialidades, está presente em toda a cadeia produtiva de produtos de origem animal (ARAÚJO et al., 2020, p. 10). Assim sendo, uma das atribuições exclusivas do Médico Veterinário é a inspeção higiênico sanitária de produtos de origem animal, a qual é responsável por garantir a Segurança dos Alimentos ao consumidor final, através da implantação de medidas de prevenção, identificação e planos de ação para eliminação de doenças transmitidas por alimentos (WHO, 2020, 2021).

Atualmente, a cadeia produtiva de alimentos é um setor essencial para a sobrevivência dos indivíduos no mundo, apresentando um padrão de qualidade elevado, principalmente no Brasil, onde há uma demanda altíssima por produtos de origem animal destinados à exportação (EMBRAPA, 2021). Além do surgimento de novas tecnologias e processos, grande parte do alto nível de exigência e estabelecimento de leis e protocolos, advém da cobrança por parte dos consumidores, os quais possuem acesso à informação e têm opinião formada a respeito das possibilidades, técnicas e processos produtivos da indústria alimentícia (WERTHEIN, 2000).

Segundo a pesquisa feita pelo Data Folha, cerca de $41 \%$ dos brasileiros são contra testes em animais, opinião predominante no público jovem (LENHARO, 2014). Entretanto, simultaneamente, existe a preocupação com os resíduos de produtos veterinários nos alimentos destinados aos humanos (ANVISA, 2018). Diante desse conflito, em garantia da saúde pública, o Médico Veterinário tem um papel fundamental nessa etapa da cadeia produtiva, sendo o único profissional capacitado para avaliar a real necessidade da realização dos testes em animais, além de garantir que o mesmo seja feito de maneira adequada as Boas Práticas Clínicas Veterinárias - BPCV (BRASIL, 2008).

\section{Antibióticos}

Todos os tipos de antimicrobianos (antibióticos, antifúngicos, antivirais) e vermífugos destinados aos animais de produção são capazes de gerar resíduos passíveis de prejudicar a saúde humana. Entretanto cada tipo de antimicrobiano possui uma particularidade e é destinado para uma espécie específica (ANVISA, 2018). O presente estudo trará informações a respeito dos antibióticos, de ação específica em bactérias, destinado ao gado de corte.

Os fármacos denominados "antibióticos" são compostos naturais ou sintéticos e seu mecanismo de ação pode ser a inibição do crescimento bacteriano, denominados bacteriostáticos ou a eliminação das bactérias bactericidas (SNUSTAD, 2017). Dentro do grupo dos antibióticos, existem variadas classes com suas especificidades de ação. A distinção pode acontecer de diversas maneiras: de acordo com a classificação química, segundo o espectro de ação ou de acordo com o efeito sobre os microrganismos (QUADRO 1) (GUIMARÃES et al., 2010).

QUADRO 1 - Classificação dos antibióticos de acordo com o efeito sobre os microrganismos

\begin{tabular}{|l|l|}
\hline \multicolumn{1}{|c|}{ ESPECTRO DE AÇÃO } & \multicolumn{1}{c|}{ ANTIBIÓTICOS } \\
\hline Ativos sobre Bactérias Gram-Positivas & $\begin{array}{l}\text { Penicilina G, Macrolídeos, } \\
\text { Bacitracina }\end{array}$ \\
\hline Ativos sobre Bactérias Gram-Negativas & Polimixinas, Aminoglicosídeos \\
\hline $\begin{array}{l}\text { Ativos sobre Bactérias Gram-Positivas e } \\
\text { Gram-Negativas } \\
\text { (Amplo Espectro) }\end{array}$ & $\begin{array}{l}\text { Cloranfenicol, Tetraciclinas, Ampicilinas, } \\
\text { Cefalosporinas }\end{array}$ \\
\hline
\end{tabular}

AGRARIAN ACADEMY, Centro Científico Conhecer - Jandaia-GO, v.8, n.16 P. 4 


\begin{tabular}{|l|l|}
\hline Ativos sobre Micobactérias & $\begin{array}{l}\text { Rifampicina, Estreptomicina, Ciclosserina, } \\
\text { Claritromicina }\end{array}$ \\
\hline $\begin{array}{l}\text { Ativos sobre Riquétsias, Micoplasmas e } \\
\text { Clamídias }\end{array}$ & Tetraciclinas, Cloranfenicol, Macrolídeos \\
\hline Ativos sobre Espiroquetas & Penicilinas, Eritromicina, Tetraciclinas \\
\hline
\end{tabular}

Fonte: Adaptado de Tavares (2014)

O antibiótico é um recurso indispensável na medicina humana, pois atua no tratamento e controle de infecções bacterianas, visando reestabelecer a saúde do indivíduo. A indicação correta é realizada após o exame de cultura e antibiograma, os quais vão determinar qual é o microrganismo exato causador da infecção, para que o antibiótico prescrito possa ter ação específica sobre esse microrganismo, de maneira eficaz e rápida (CEARÁ, 2021).

Entretanto, na prática, nem sempre essa é a conduta médica. Em muitos casos não é solicitado o exame de cultura e antibiograma, e o médico prescreve um antibiótico de amplo espectro ou de escolha. Essa prescrição "aleatória" coloca em risco a saúde do indivíduo, pois o antibiótico pode ser correto e ter ação efetiva ou pode ser o antibiótico inadequado que não é eficaz no controle da infecção, mas apenas seleciona as bactérias e favorece a criação de resistência antimicrobiana (CEARÁ, 2021). Partindo desse princípio, no Brasil, criou-se a necessidade de sancionar a lei que proíbe a compra de antibióticos sem prescrição médica, atitude muito comum na rotina do brasileiro (BRASIL, 2006).

O uso de antimicrobianos na medicina veterinária, da mesma maneira, sempre ocorreu de forma terapêutica com o intuito de zelar pela saúde do animal. Entretanto, desde a década de 50, descobriu-se que o uso de maneira preventiva provoca melhora no desempenho zootécnico dos animais de produção. Resulta em aumento da qualidade, atribuindo mais valor e gerando menos perdas nos rebanhos comerciais. Desde então, os APCs (antibióticos promotores de crescimento) passaram a ser de uso regular através de sua presença na dieta dos animais (GONZALES et al., 2017).

\section{Resistência Antimicrobiana Humana}

Segundo um estudo realizado pela World Health Organization (2019), cerca de 700 mil pessoas morrem por ano, devido à resistência bacteriana e estima-se que até 2050 , os números chegarão a 10 milhões de mortes. A resistência antimicrobiana (RAM) tem se tornado uma das maiores preocupações mundiais há mais de duas décadas (OMS, 2012).

Sabe-se que a RAM ocorre naturalmente ao longo do tempo, causada através da mutação espontânea dos genes de microrganismos (bactérias, fungos, vírus e parasitas). Entretanto, o contato excessivo e indiscriminado dos antimicrobianos aceleram a RAM, através de sua ação seletiva (OPAS, 2021). A grande preocupação é que a exposição crônica a doses subagudas de resíduos seja prejudicial à saúde humana (ANVISA, 2018).

O crescente risco de uma crise na saúde pública faz com que os países se unam regularmente para o planejamento de planos de ação a serem adotados em cada país visando conter a RAM (MOTA et al., 2005). As resoluções sempre destacam a necessidade de implementar sistemas regulatórios mais fortes e apoiar programas de conscientização para o uso responsável e prudente de antimicrobianos por profissionais de saúde humana, animal e vegetal, além de enfatizarem a necessidade de eliminar urgentemente o uso de antimicrobianos de 
importância crítica como promotores de crescimento na agricultura (WHO, 2019; BRASIL, 2021a, 2021b).

\title{
Efeito Residual
}

Ainda que sob supervisão de Médicos Veterinários e aplicação de Boas Práticas Veterinárias, o uso frequente desses medicamentos pode gerar resíduos nos alimentos de origem animal (carne, leite e ovos). Muitos dos antibióticos veterinários visam eliminar bactérias que também fazem parte da microbiota humana e são de grande interesse da medicina humana. Dessa maneira, a cada vez que o indivíduo consumir carne (ou qualquer outro produto de origem animal), o fármaco residual constantemente seleciona bactérias e acelera a RAM desse indivíduo. Ainda que seja uma quantidade mínima do resíduo, sua ingestão constante através dos alimentos, pode o tornar resistente a antibióticos que nunca (ou poucas vezes) tenha ingerido durante alguma intervenção médica. Essa resistência dificulta e muitas vezes impossibilita o tratamento medicamentoso de determinadas doenças que 0 indivíduo possa vir a apresentar no futuro (ANVISA, 2018).

\section{Período de Carência}

Com o objetivo de evitar que haja resíduos de medicamentos veterinários (RMV) em produtos de origem animal é necessário estabelecer o período de carência de abate, ou seja, o tempo que se deve aguardar para que o abate dos animais de produção que tenham sido expostos aos antibióticos não traga riscos à saúde humana. Essa determinação busca estimar, prever e prevenir a ocorrência de efeitos adversos à saúde humana através da realização de testes toxicológicos (ANVISA, 2018). Para que a comercialização dos produtos de origem animal aconteça, a legislação brasileira prevê e estabelece dois parâmetros a serem seguidos: ingestão diária aceitável (IDA) e os limites máximos de resíduos em alimentos (LMR). O órgão que regularmente atualiza e regulamenta esses parâmetros é a Agência Nacional de Vigilância Sanitária (ANVISA), porém o órgão responsável por fiscalizar, registrar e renovar as licenças desses fármacos é o Ministério da Agricultura, Pecuária e Abastecimento (MAPA).

IDA é a quantidade estimada de insumo farmacêutico ativo e/ou seus metabólitos que pode ser ingerida diariamente ao longo da vida sem risco apreciável à saúde humana (ANVISA, 2018, p. 7).

\begin{abstract}
LMR é a concentração máxima de resíduo, resultante do emprego de um produto de uso veterinário, legalmente permitida em alimentos. Considerase que esse resíduo não possui qualquer efeito adverso à saúde humana se consumido diariamente ao longo da vida (ANVISA, 2018, p. 7).
\end{abstract}

Em alguns países, existem diversas organizações realizando estudos para determinação dos LMRs que não seriam prejudiciais à saúde humana. O mais completo é o Codex Alimentarius, programa criado em 1963, em conjunto a OMS e a FAO (Food and Agriculture Organization), do qual o Brasil faz parte desde 1970. O objetivo desse programa é produzir guias e diretrizes internacionais na área de alimentos (ANVISA, 2018; FAO; WHO, 2019b).

Atualmente, apesar de compilar alguns dados na Instrução Normativa (IN) N51, de 29 de dezembro de 2019 (QUADRO 2), segundo a ANVISA (2018) a principal referência para a determinação dos LMRs permitidos no Brasil seria o Codex Alimentarius. Contudo, na falta de dados no Codex Alimentarius, a recomendação é seguir os dados de outras agências com reconhecimento e AGRARIAN ACADEMY, Centro Científico Conhecer - Jandaia-GO, v.8, n.16 P. 6 
prestígio internacional na avaliação dos riscos dos produtos veterinários, são: EMA (European Medicines Agency), FDA (Federal Food, Drug, and Cosmetic Act), FSC Japan (Food Safety Commission of Japan), APVMA (Australian Pesticides and Veterinary Medicines Authority) e Health Canada (FAO; WHO, 2021).

QUADRO 2 - Antibióticos utilizados em bovinos de corte e seus respectivos LMRs permitidos pela legislação brasileira

\begin{tabular}{|c|c|c|c|c|c|}
\hline $\begin{array}{c}\text { INSUMO } \\
\text { FARMACÊUTICO } \\
\text { ATIVO }\end{array}$ & $\begin{array}{c}\text { RESÍDUO } \\
\text { MARCADOR }\end{array}$ & $\begin{array}{c}\text { CLASSE } \\
\text { TERAPÊUTICA }\end{array}$ & TECIDO & $\begin{array}{l}\text { LMR } \\
\mu g / k g\end{array}$ & $\begin{array}{c}\text { REFERÊNC } \\
\text { IA }\end{array}$ \\
\hline \multirow{4}{*}{ AMOXICILINA } & \multirow[t]{4}{*}{ Amoxicilina } & \multirow{4}{*}{$\begin{array}{c}\text { Penicilinas } \\
\text { natural, } \\
\text { aminopenicilinas } \\
e \\
\text { antipseudomona }\end{array}$} & Músculo & 50 & \multirow[t]{4}{*}{ CODEX } \\
\hline & & & Fígado & 50 & \\
\hline & & & Rim & 50 & \\
\hline & & & Gordura & 50 & \\
\hline \multirow[t]{4}{*}{ AMPICILINA } & \multirow[t]{4}{*}{ Ampicilina } & \multirow{4}{*}{$\begin{array}{c}\text { Penicilinas } \\
\text { natural, } \\
\text { aminopenicilinas } \\
e \\
\text { antipseudomona }\end{array}$} & Músculo & 50 & \multirow[t]{4}{*}{ UE } \\
\hline & & & Fígado & 50 & \\
\hline & & & $\operatorname{Rim}$ & 50 & \\
\hline & & & Gordura & 50 & \\
\hline \multirow[t]{4}{*}{ APRAMICINA $^{\top}$} & \multirow[t]{4}{*}{ Apramicina } & \multirow{4}{*}{$\begin{array}{c}\text { Aminoglicosídeo } \\
s\end{array}$} & Músculo & 1000 & \multirow[t]{4}{*}{ UE } \\
\hline & & & Fígado & 10000 & \\
\hline & & & Rim & 20000 & \\
\hline & & & Gordura & 1000 & \\
\hline \multirow[t]{3}{*}{ BENZILPENICILINA } & \multirow[t]{3}{*}{ Benzilpenicilina } & \multirow{3}{*}{$\begin{array}{c}\text { Penicilinas } \\
\text { natural, } \\
\text { aminopenicilinas } \\
e \\
\text { antipseudomona }\end{array}$} & Músculo & 50 & \multirow[t]{3}{*}{ CODEX } \\
\hline & & & Fígado & 50 & \\
\hline & & & Rim & 50 & \\
\hline \multirow[t]{4}{*}{ CEFALEXINA } & \multirow[t]{4}{*}{ Cefalexina } & \multirow{4}{*}{$\begin{array}{c}\text { Cefalosporinas } \\
\left(1^{\circ} \text { e } 2^{\circ}\right. \\
\text { Geração) }\end{array}$} & Músculo & 200 & \multirow[t]{4}{*}{ UE } \\
\hline & & & Fígado & 200 & \\
\hline & & & Rim & 1000 & \\
\hline & & & Gordura & 200 & \\
\hline \multirow[t]{3}{*}{ CEFAPIRINA } & \multirow{3}{*}{$\begin{array}{c}\text { Soma de } \\
\text { Cefeprina e } \\
\text { disacetilcefaprina }\end{array}$} & \multirow{3}{*}{$\begin{array}{c}\text { Cefalosporínico } \\
\text { s } \\
\text { (1ªeração) }\end{array}$} & Músculo & 50 & \multirow[t]{3}{*}{ UE } \\
\hline & & & Rim & 100 & \\
\hline & & & Gordura & 50 & \\
\hline \multirow[t]{4}{*}{ CEFQUINOMA } & \multirow[t]{4}{*}{ Cefquinoma } & \multirow{4}{*}{$\begin{array}{c}\text { Cefalosporinas } \\
\left(3^{\circ}, 4^{\circ} \text { e } 5^{\circ}\right. \\
\text { Geração) }\end{array}$} & Músculo & 50 & UE \\
\hline & & & Fígado & 100 & \\
\hline & & & Rim & 200 & \\
\hline & & & Gordura & 50 & \\
\hline CEFTIOFUR & Desfuroil ceftiofur & Cefalosporinas & Músculo & 1000 & CODEX \\
\hline & & $\left(3^{\circ}, 4^{\circ}\right.$ e $5^{\circ}$ & Fígado & 2000 & \\
\hline & & Geração) & Rim & 6000 & \\
\hline & & & Gordura & 2000 & \\
\hline CLORTETRACICLIN & Tetraciclina & Tetraciclinas & Músculo & 200 & CODEX \\
\hline 0 & & & Fígado & 600 & \\
\hline & & & $\operatorname{Rim}$ & 1200 & \\
\hline CLOXACILINA & Cloxacilina & Penicilinas & Músculo & 300 & UE \\
\hline & & antistafiloccócic & Fígado & 300 & \\
\hline & & & $\operatorname{Rim}$ & 300 & \\
\hline & & & Gordura & 300 & \\
\hline COLISTINA & Soma de Colistina & Poliaminas & Músculo & 150 & CODEX \\
\hline
\end{tabular}

Exclusivo para uso oral; 


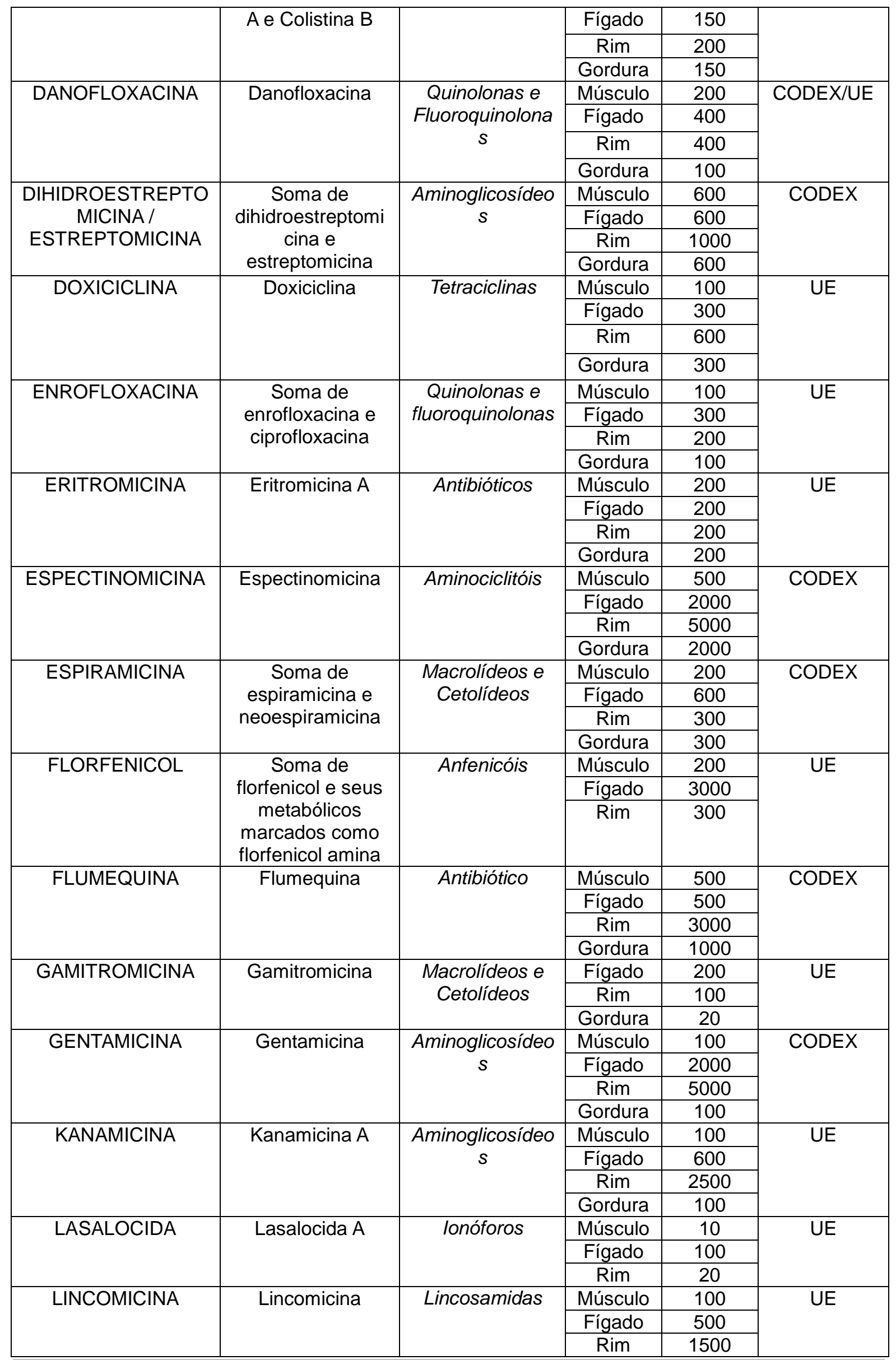




\begin{tabular}{|c|c|c|c|c|c|}
\hline & & & Gordura & 50 & \\
\hline MARBOFLOXACINA & Marvofloxacina & Antibiótico & Músculo & 150 & UE \\
\hline \multirow[t]{4}{*}{ MONOENSINA } & \multirow[t]{4}{*}{ Monoensina } & \multirow[t]{4}{*}{ Ionóforos } & Músculo & 10 & \multirow[t]{4}{*}{ CODEX } \\
\hline & & & Fígado & 100 & \\
\hline & & & Rim & 10 & \\
\hline & & & Gordura & 100 & \\
\hline \multirow[t]{4}{*}{ NAFCILINA $^{2}$} & \multirow[t]{4}{*}{ Naficllina } & \multirow{4}{*}{$\begin{array}{c}\text { Penicilinas } \\
\text { antisafilocócicas }\end{array}$} & Músculo & 300 & \multirow[t]{4}{*}{ UE } \\
\hline & & & Fígado & 300 & \\
\hline & & & $\operatorname{Rim}$ & 300 & \\
\hline & & & Gordura & 300 & \\
\hline \multirow[t]{4}{*}{ NARASINA } & \multirow[t]{4}{*}{ Narasina A } & \multirow[t]{4}{*}{ lonóforos } & Músculo & 15 & \multirow[t]{4}{*}{ CODEX } \\
\hline & & & Fígado & 50 & \\
\hline & & & Rim & 15 & \\
\hline & & & Gordura & 50 & \\
\hline \multirow[t]{4}{*}{ NEOMICINA } & \multirow[t]{4}{*}{ Neomicina } & \multirow{4}{*}{$\begin{array}{c}\text { Aminoglicosídeo } \\
\mathrm{s}\end{array}$} & Músculo & 500 & \multirow[t]{4}{*}{ CODEX } \\
\hline & & & Fígado & 500 & \\
\hline & & & Rim & 10000 & \\
\hline & & & Gordura & 500 & \\
\hline \multirow[t]{3}{*}{ OXITETRACICLINA } & \multirow[t]{3}{*}{ Tetraciclina } & \multirow[t]{3}{*}{ Tetraciclinas } & Músculo & 200 & \multirow[t]{3}{*}{ CODEX } \\
\hline & & & Fígado & 600 & \\
\hline & & & Rim & 1200 & \\
\hline \multirow[t]{4}{*}{ PIRLIMICINA } & Pirlimicina & Antibiótico & Músculo & 100 & CODEX \\
\hline & & & Fígado & 1000 & \\
\hline & & & $\operatorname{Rim}$ & 400 & \\
\hline & & & Gordura & 100 & \\
\hline SULFONAMIDAS ${ }^{3}$ & Substância & Sulfonamidas & Músculo & 100 & UE \\
\hline & principal & & Fígado & 100 & \\
\hline & & & $\operatorname{Rim}$ & 100 & \\
\hline & & & Gordura & 100 & \\
\hline TETRACICLINA & Soma da & Tetraciclinas & Músculo & 200 & CODEX \\
\hline & subtância orginal & & Fígado & 600 & \\
\hline & & & Rim & 1200 & \\
\hline TIAMULINA & Soma de & Pleuromutilinas & Músculo & 100 & JAPÃO \\
\hline & metabólitos que & & Fígado & 500 & \\
\hline & podem ser & & $\operatorname{Rim}$ & 100 & \\
\hline & $\begin{array}{l}\text { hidrolisados a 8- } \\
\alpha \text {-hifroxi-mutilina }\end{array}$ & & Gordura & 100 & \\
\hline TILDIPIROSINA & Tildipirosina & Macrolídeos e & Músculo & 400 & UE \\
\hline & & Cetolídeos & Fígado & 2000 & \\
\hline & & & $\operatorname{Rim}$ & 3000 & \\
\hline & & & Gordura & 200 & \\
\hline TILMICOSINA & Tilmicosina & Macrolídeos e & Músculo & 100 & CODEX \\
\hline & & Cetolídeos & Fígado & 1000 & \\
\hline & & & Rim & 300 & \\
\hline & & & Gordura & 100 & \\
\hline TILOSINA & Tilosina A & Macrolídeos e & Músculo & 100 & CODEX \\
\hline & & Cetolídeos & Fígado & 100 & \\
\hline & & & Rim & 100 & \\
\hline & & & Gordura & 100 & \\
\hline TIMETOPRIMA & Timetoprima & Sulfonamidas, & Músculo & 50 & UE \\
\hline & & inibidores & Fígado & 50 & \\
\hline & & dihidrofolato & Rim & 50 & \\
\hline
\end{tabular}

2 Exclusivamente para uso intramamário;

3 O total combinado dos resúdos de todas as substâncias do grupo das sulfonamidas não deve ultrapassar $100 \mu \mathrm{g} / \mathrm{kg}$. 


\begin{tabular}{|c|c|c|c|c|c|}
\hline & & $\begin{array}{c}\text { redutase e } \\
\text { combinações }\end{array}$ & Gordura & 50 & \\
\hline \multirow[t]{8}{*}{ TULATROMICINA } & \multirow{8}{*}{$\begin{array}{c}\text { (2R,3S,4R,5R,8R, } \\
\text { 10R,11R,12S,13S } \\
\text {,14R) - 2-etil- } \\
\text { 3,4,10,13-tetra- } \\
\text { hidroxi3,5,8,10,12 } \\
\text {,14-hexametil-11- } \\
\text { [[3,4,6- trideoxi-3- } \\
\text { (dimeti-lamino)- } \\
\beta-\mathrm{D}-\mathrm{xilohexopir-} \\
\text { anosil]oxy]-1-oxa- } \\
\text { 6- azaciclopenta- } \\
\text { decan-15-ona } \\
\text { expresso como } \\
\text { equivalentes de } \\
\text { tulatromicina }\end{array}$} & \multirow{8}{*}{$\begin{array}{c}\text { Macrolídeos e } \\
\text { Cetolídeos }\end{array}$} & Músculo & 300 & \multirow[t]{8}{*}{ UE } \\
\hline & & & Fígado & 4500 & \\
\hline & & & $\operatorname{Rim}$ & 3000 & \\
\hline & & & Gordura & 200 & \\
\hline & & & & & \\
\hline & & & & & \\
\hline & & & & & \\
\hline & & & & & \\
\hline
\end{tabular}

Fonte: Adaptado de BRASIL (2020)

\section{Pesquisa Clínica Veterinária}

É fato de que o Brasil possui um cenário aquecido e promissor ao se tratar de proteína animal. No país a população de animais se torna cada vez mais expressiva, seja ela de pet (cães e gatos) ou animais de produção (rebanho bovino, suíno, caprinos, equinos, peixes e aves ornamentais, dentre outros). Naturalmente o mercado interno exige uma alta demanda por novos produtos veterinários. Além do mais, o fornecimento de proteína animal ao exterior condiciona que o Brasil se adeque às exigências do mercado externo. Sendo assim, visando manter elevada a qualidade de fabricação, uso e comércio desses produtos a legislação brasileira prevê a realização de testes para garantir que os produtos são eficazes para a finalidade proposta, são seguros para o uso nos animais e possuem período de carência conhecido (produtos destinados aos animais produtores de alimentos: carne, leite e ovos) (CRMV, 2021).

A pesquisa clínica veterinária, consiste em um estudo clínico realizado na espécie-alvo para testar pelo menos uma hipótese relevante para a finalidade proposta de um produto veterinário sob investigação, o qual gera dossiês destinados à análise e aprovação em casos de renovação de licença e registro de novos produtos veterinários. Segundo o Decreto $N^{\circ}$ 5.053, de 2 de abril de 2004, essa fiscalização é de responsabilidade da Coordenação de Registro e Fiscalização de Produtos Veterinários (CPV), unidade pertencente ao Departamento de Saúde Animal (MAPA) (BRASIL, 2004).

A legislação brasileira não possui uma norma oficial, unificada e abrangente a respeito do teste em animais, porém a Lei Arouca ( $\mathrm{N}^{\circ} 11.794$, de 08 de outubro de 2008) estabelece e preconiza algumas instruções e exigências pontuais (BRASIL, 2008). Uma recomendação indispensável é que os testes ocorram sob a ótica das boas práticas clínicas veterinárias - BPCV. O MAPA recomenda que os estudos sejam conduzidos de acordo com os guias internacionais de BPCV publicados pelo VICH (Conferência Internacional sobre Harmonização de Requisitos Técnicos para Registro de Produtos Veterinários), desenvolvido desde o ano de 1996, através da avaliação dos guias e das práticas realizadas em países da União Europeia, Japão e Estados Unidos (CRMV, 2021).

Todos os tipos de estudo (eficácia, segurança ou resíduo) devem seguir o guia de boas práticas clínicas VICH GL9, o qual sempre preconiza um estudo cego 
( $\mathrm{VICH}, 2000)$. Os estudos precisam zelar pela ética e cuidado com os animais seguindo os princípios dos "3 Rs" (NC3Rs, 2021):

1. Substituição (Replacement) métodos alternativos;

2. Redução (Reduction) redução do número de exemplares;

3. Refinamento (Refinement) minimização do sofrimento dos animais;

A pesquisa deve ocorrer sempre de maneira racional minimizando o uso de animais e o seu sofrimento sem comprometer a qualidade do trabalho científico, além de seguir rigidamente as normas éticas em relação ao uso de animais de laboratório em pesquisa. A prática desses estudos deve ser resumida a Responsibility, ou seja, o uso responsável de animais em um experimento deve ser feito com responsabilidade (NC3Rs, 2021).

O Ministério da Ciência e Tecnologia possui a responsabilidade de fiscalizar e implementar as medidas sancionadas na Lei Arouca. $\mathrm{O}$ artigo $4^{\circ}$ da lei estabeleceu a criação do CONCEA (Conselho Nacional de Controle de Experimentação Animal), responsável, entre outras funções, por fiscalizar, revisar processos e implementar medidas visando o cumprimento de BPCV às pesquisas científicas com animais no País.

\footnotetext{
Art. $5^{\circ}$ - Compete ao CONCEA:

I - Formular e zelar pelo cumprimento das normas relativas à utilização humanitária de animais com finalidade de ensino e pesquisa científica;

II - Credenciar instituições para criação ou utilização de animais em ensino e pesquisa científica;

III - Monitorar e avaliar a introdução de técnicas alternativas que substituam a utilização de animais em ensino e pesquisa;

IV - Estabelecer e rever, periodicamente, as normas para uso e cuidados com animais para ensino e pesquisa, em consonância com as convenções internacionais das quais o Brasil seja signatário;

$V$ - Estabelecer e rever, periodicamente, normas técnicas para instalação e funcionamento de centros de criação, de biotérios e de laboratórios de experimentação animal, bem como sobre as condições de trabalho em tais instalações;

$\mathrm{VI}$ - Estabelecer e rever, periodicamente, normas para credenciamento de instituições que criem ou utilizem animais para ensino e pesquisa;

VII - Manter cadastro atualizado dos procedimentos de ensino e pesquisa realizados ou em andamento no País, assim como dos pesquisadores, a partir de informações remetidas pelas Comissões de Etica no Uso de Animais - CEUAs, de que trata o art. 80 desta Lei;

VIII - Apreciar e decidir recursos interpostos contra decisões das CEUAs;

IX - Elaborar e submeter ao Ministro de Estado da Ciência e Tecnologia, para aprovação, o seu regimento interno;

$X$ - Assessorar o Poder Executivo a respeito das atividades de ensino e pesquisa tratadas nesta Lei (BRASIL, 2008).
}

Destaca-se os incisos II e VII. O inciso II é fundamental para que qualquer empresa ou instituição de educação possa dar início a um estudo clínico. Os interessados devem realizar a inscrição no CONCEA e os manter sempre atualizados. O inciso VII, ressalta que a atualização não deve ser apenas administrativa, mas principalmente na submissão e detalhamento dos estudos em andamento e realizados, além da aprovação e decisões das CEUAs (Comissões de ética no Uso de Animais) das respectivas instituições em cada teste a ser realizado (BRASIL, 2008). 
Segundo a Lei 11.794, é indispensável que cada instituição possua uma CEUA, na qual todos os estudos devem ser submetidos visando aprovação ou não da execução do estudo clínico. A CEUA detém a responsabilidade de aprovar ou não a necessidade e/ou a metodologia a ser abordada nos testes. Todo o protocolo de estudo deve dispor de aprovação para ter início. A composição da CEUA é préestabelecida pela legislação à fim de ser imparcial:

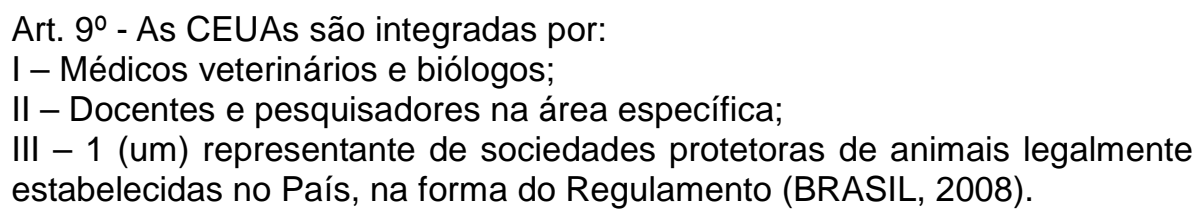

A Pesquisa Clínica Veterinária é uma atividade séria que engloba a atuação de profissionais de diversos setores e áreas de atuação, e perante a legislação brasileira é submetida a diversos órgãos, os quais estão sintetizados na FIGURA 3 (BRASIL, 2009; CRMV, 2021).

FIGURA 3 - Órgãos relacionados com a pesquisa clínica veterinária

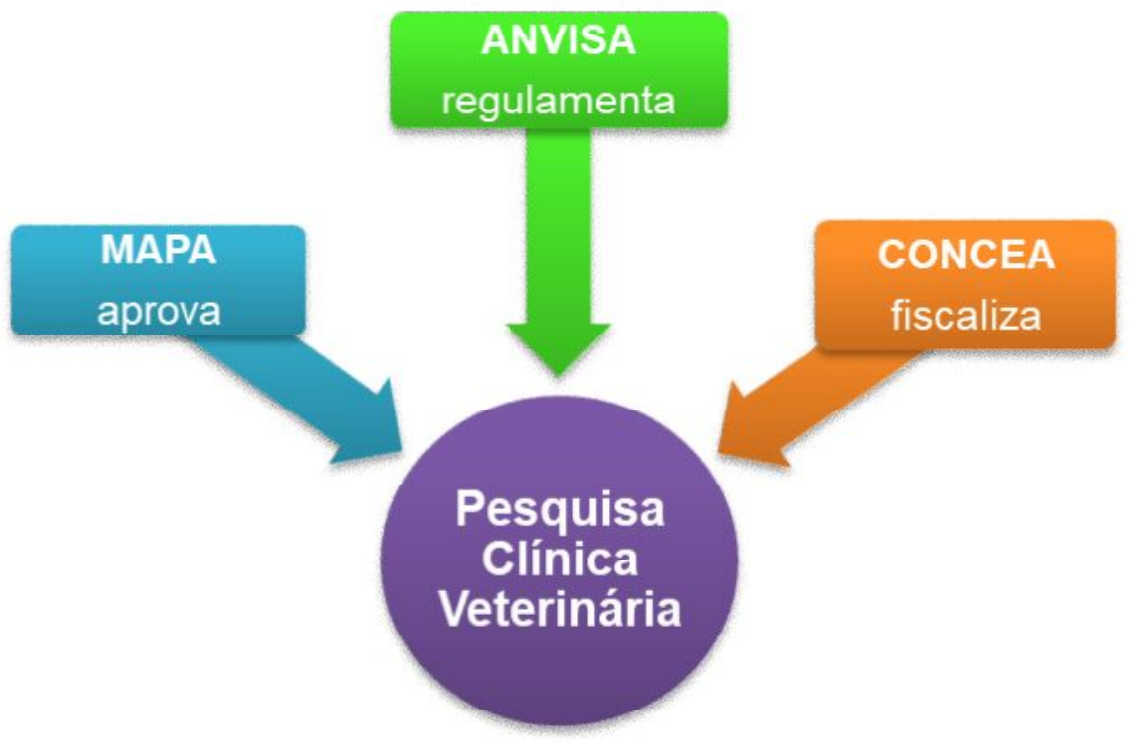

Fonte: Elaborado pelos autores (2021)

\section{Metodologia do Estudo Clínico}

Cada tipo de estudo clínico possui uma metodologia específica e focada em seu objetivo. Apesar disso, em todos os estudos o objetivo final é a produção de uma pesquisa eficiente que garanta a rastreabilidade, precisão, integridade e correção dos dados do Produto Veterinário (PV) em análise. É essencial que o conceito de Responsability seja aplicado em todo o processo, desde a organização do cronograma até a avaliação dos dados coletados sejam conduzidos com qualidade ética, científica e técnica, para que atenda aos requisitos estabelecidos pelas autoridades regulatórias e não seja necessário a execução de um novo estudo (CRMV, 2021).

Os estudos devem iniciar com a elaboração de um protocolo de pesquisa, ou seja, "Documento contemplando a descrição da pesquisa em seus aspectos fundamentais, informações relativas ao sujeito da pesquisa, à qualificação dos 
pesquisadores e à todas as instâncias responsáveis" (BRASIL, 1996). Os protocolos devem ser delineados adequadamente as exigências das autoridades regulatórias, incluindo justificativas, desfechos, critérios de inclusão e exclusão, análises estatísticas, procedimentos que assegurem o bem-estar animal e os possíveis efeitos ao meio ambiente e também a população envolvida na condução do estudo. Todos os protocolos carecem de aprovação de suas CEUAs, a qual deve estar registrada no projeto de pesquisa (CRMV, 2021).

Os colaboradores envolvidos na execução de um estudo clínico devem ser qualificados e apresentar total domínio sobre funções da etapa que é responsável. Para garantir a rastreabilidade e veracidade do estudo, todos os indivíduos devem registrar e relatar os dados e/ou observações pertinentes a sua função de maneira clara, didática, precisa e instantânea possível em seus respectivos formulários e relatórios previstos no protocolo. Sem os registros, é impossível validar os dados. Do mesmo modo que os profissionais envolvidos tanto na elaboração dos protocolos de um estudo clínico, como na avaliação dos relatórios produzidos pós estudos clínicos, devem ser qualificados e dominar os conceitos de boas práticas clínicas veterinárias a serem incorporados no projeto, além das legislações e dados relevantes determinados pela legislação brasileira e órgãos regulatórios (CRMV, 2021).

Outro fator importante é que todos os indivíduos envolvidos no projeto tenham conhecimento a respeito das boas práticas de fabricação do PV em questão, para que o manuseio, armazenamento ocorra de maneira correta e não invalide o estudo (CRMV, 2021). Em suma, os profissionais devem garantir a qualidade tanto na elaboração, como na execução do projeto, para que o mesmo possa ser autêntico e passível de validação das autoridades e tenha uso invulnerável aos animais e, em alguns casos, toda sua cadeia produtiva (CRMV, 2021).

Os estudos prévios e a qualificação profissional, objetiva minimizar, porém não inibe a ocorrência de alguma possível intercorrência durante algum estudo clínico, entretanto para validar o estudo, é necessário que os delineamentos preconizem a possibilidade e descrevam o funcionamento de emendas e/ou desvios acrescentados em seus protocolos (BRASIL, 2009):

Emenda ao protocolo: descrição por escrito de qualquer alteração ao protocolo, que deve ser aprovada pelo pesquisador e pelo patrocinador, antes da sua implementação. As emendas que comprometem significativamente a segurança dos animais-alvo, o âmbito da pesquisa ou a qualidade científica do estudo necessitam de aprovação adicional pela CEUA da instituição, antes de sua implementação. Essas exigências para aprovação não devem impedir a ação imediata por parte do pesquisador ou do patrocinador no interesse de preservar a segurança de todos os animais admitidos no estudo.

Desvio do protocolo: um afastamento dos procedimentos declarados no protocolo. Os desvios do protocolo devem ser registrados, acompanhados de uma justificativa técnica, assinados e datados pelo pesquisador, descrevendo o desvio, a razão para esta ocorrência (se identificável) e os procedimentos a serem adotados em virtude do desvio.

O conceito de Responsability deve estar sempre em primeiro lugar, pois o estudo ocorre com animais vivos, os quais devem ter sua segurança preservada. Alguns comportamentos e reações não podem ser previstos e se ocorrem, devem ser levados em consideração e se necessário, alguns procedimentos devem ser alterados durante o estudo. 


\section{Etapas do Estudo de Resíduo - Tecidos}

A determinação do período de carência sobre variação de acordo com a formulação medicamentosa, a via de administração e a espécie animal tratada. Logo, os períodos de carência específicos deverão ser calculados para cada formulação medicamentosa destinada a cada espécie de animais de produção (VICH, 2015).

A avaliação dos resíduos na espécie bovina é feita nas matrizes de maior consumo pela população: músculo, fígado, rim e gordura. Essa avaliação é composta de cinco etapas: desenvolvimento do protocolo, etapa experimental (realizada a campo), etapa laboratorial (analítica) e relatório final do estudo $(\mathrm{VICH}$, 2015; CRMV, 2021).

\section{1) Desenvolvimento do Protocolo}

Esta etapa contempla a descrição detalhada do objetivo, cronograma, metodologia e condução do estudo, a qual deve ser aprovada pelo patrocinador e CEUA (dados obrigatórios descritos nos QUADROS 3 e 4). Todos os procedimentos do estudo devem buscar seguir os Procedimentos Operacionais Padrão (POPs) para minimizar erros (VICH, 2015; CRMV, 2021).

QUADRO 3 - Profissionais envolvidos no estudo

\begin{tabular}{|l|l|}
\hline DENOMINAÇÃO & \multicolumn{1}{c|}{ FUNÇÃO } \\
\hline Investigador & $\begin{array}{l}\text { Médico Veterinário responsável pela condução do estudo, } \\
\text { participando da etapa experimental do estudo }\end{array}$ \\
\hline Patrocinador & $\begin{array}{l}\text { Indivíduo ou instituição que solicita e arca financeiramente pelo } \\
\text { ensaio clínico }\end{array}$ \\
\hline Monitor & $\begin{array}{l}\text { Indivíduo indicado pelo patrocinador para acompanhar e fiscalizar a } \\
\text { realização e o cumprimento dos prazos e atividades previstas no } \\
\text { protocolo }\end{array}$ \\
\hline
\end{tabular}

Fonte: Adaptado de CRMV (2021) e VICH (2015)

QUADRO 4 - Tópicos obrigatórios no protocolo

\begin{tabular}{|c|c|}
\hline TÓPICO & CONTEÚDO \\
\hline $\begin{array}{l}\text { Informações } \\
\text { gerais }\end{array}$ & $\begin{array}{l}\text { Descrição do local do estudo, dados dos profissionais envolvidos, } \\
\text { objetivo e tipo do estudo, resumo do PV em análise (dose, via de } \\
\text { administração, classificação), espécie-alvo; }\end{array}$ \\
\hline $\begin{array}{l}\text { Delineamento } \\
\text { do Estudo }\end{array}$ & $\begin{array}{l}\text { Introdução e argumentação científica a respeito da importância e uso do } \\
\text { PV em estudo, argumentos sobre os parâmetros de avaliação, descrição } \\
\text { das medidas utilizadas para minimizar o uso de animais vivos no estudo, } \\
\text { descrição do tratamento e da posologia administrada, duração da } \\
\text { participação dos animais experimentais no estudo, informações a } \\
\text { respeito do registro de cada etapa do estudo e critérios de suspensão do } \\
\text { estudo; }\end{array}$ \\
\hline Animais & $\begin{array}{l}\text { Características a serem selecionadas, procedência dos animais, } \\
\text { quantidade dos animais e forma de randomização, critérios de } \\
\text { inclusão/exclusão/ ou retirada dos animais, manejo e alojamento dos } \\
\text { animais e descrição do tratamento dos animais com o PV. Em todas } \\
\text { essas informações, deve constar qual o formulário de registro das } \\
\text { informações de cada animal; }\end{array}$ \\
\hline $\begin{array}{l}\text { Análise dos } \\
\text { Resíduos }\end{array}$ & $\begin{array}{l}\text { Explicação e embasamento científico de como será feita a avaliação do } \\
\text { efeito residual desses fármacos em cada matriz }\end{array}$ \\
\hline $\begin{array}{l}\text { Análise } \\
\text { Estatística }\end{array}$ & Descrição da obtenção dos resultados do teste em questão. \\
\hline
\end{tabular}

Fonte: Adaptado de VICH (2015) e CRMV (2021) 


\section{2) Etapa Experimental}

Após aprovação total do protocolo pela CEUA o investigador dá início a todas as etapas previstas no cronograma, seguindo à risca todas as informações. Caso haja a necessidade de algum desvio ou emenda, o monitor e patrocinador devem ser sempre notificados (VICH, 2015; CRMV, 2021).

Nessa etapa, o monitor pode acompanhar e entrar em contato com o investigador solicitando visitas presenciais ao local de estudo ou atualização a respeito dos processos. Da mesma maneira em que o investigador pode comunicar ao monitor, eventuais intercorrências (VICH, 2015; CRMV, 2021).

O cronograma e as ações desta etapa vão variar de acordo com o PV em questão e as suas respectivas exigências. Porém, para avaliação dos resíduos nas matrizes, o guia GL48 (VICH, 2015) estabelece algumas informações comuns a todos os testes de bovinos (QUADROS 5 e 6).

QUADRO 5 - Elementos obrigatórios na etapa experimental

\section{ELEMENTOS OBRIGATÓRIOS}

Não é necessário o uso de animal controle

Deve-se utilizar maior dosagem prevista e o maior período de administração determinado em bula no PV

No caso de vias de administração múltiplas, deve ser realizado um estudo específico para cada via de administração

O peso dos animais deve ser entre 250 a $400 \mathrm{~kg}$;

Produtos de administração múltipla, deve-se alternar a aplicação entre o lado direito e esquerdo

No mínimo 16 animais devem ser avaliados (maioria dos testes) e submetidos exatamente ao mesmo tratamento

Deve-se fazer grupo de 4 animais

Deve-se estabelecer 4 intervalos de tempo de eutanásia

Processamento das Amostras:

- Utilizar uma luva e uma faca por animal e por tecido a ser coletado;

- A coleta da amostra dos tecidos deve seguir o padrão descrito no QUADRO 7.

Fonte: Adaptado de $\mathrm{VICH}$ (2015)

QUADRO 6 - Observações importantes sobre a etapa experimental

\section{OBSERVAÇÕES}

Recomenda-se realizar a coleta das amostras, logo após a eutanásia;

Se as amostras não forem processadas imediatamente após abate, estas deverão ser mantidas em condições de congelamento e separadas uma das outras;

Caso o patrocinador solicite o armazenamento de parte da amostra (caso de contraprova), é de sua total responsabilidade demonstrar e garantir a estabilidade dos resíduos.

Fonte: Adaptado de $\mathrm{VICH}$ (2015)

QUADRO 7 - Coleta da amostra de tecidos

\begin{tabular}{|c|l|}
\hline TECIDO & \multicolumn{1}{|c|}{ CORTE } \\
\hline Músculo & LOMBO $\rightarrow$ Núcleo do tecido muscular = 500 $\mathrm{g}$ \\
$\begin{array}{c}\text { (Local/Sítio de } \\
\text { aplicação) }\end{array}$ & $10 \mathrm{~cm}$ de diâmetro $\times 6 \mathrm{~cm}$ profundo para IM (intramuscular); \\
\hline Fígado & Secção de diâmetransversal de lóbulos \\
\hline Rim & Órgãos inteiros \\
\hline Gordura & Peri renal \\
\hline
\end{tabular}

Fonte: Adaptado de $\mathrm{VICH}$ (2015) 


\section{3) Etapa Laboratorial}

A finalidade dessa etapa é determinar o período de carência, ou seja, qual o intervalo de tempo desde o último dia após aplicação do ativo até o momento em que os tecidos provenientes dos animais medicados possam ser ingeridos pelo ser humano. As amostras são processadas laboratorialmente e analisadas em softwares específicos. Cada animal tem cada amostra avaliada diariamente. O cálculo ocorre no momento em que $95 \%$ dos animais apresentam as quantidades de resíduo abaixo dos valores de LMR estabelecidos para cada tecido: músculo, fígado, rim e gordura ( $\mathrm{VICH}, 2015)$.

FIGURA 4 - Representação gráfica da determinação do período de carência de um antibiótico

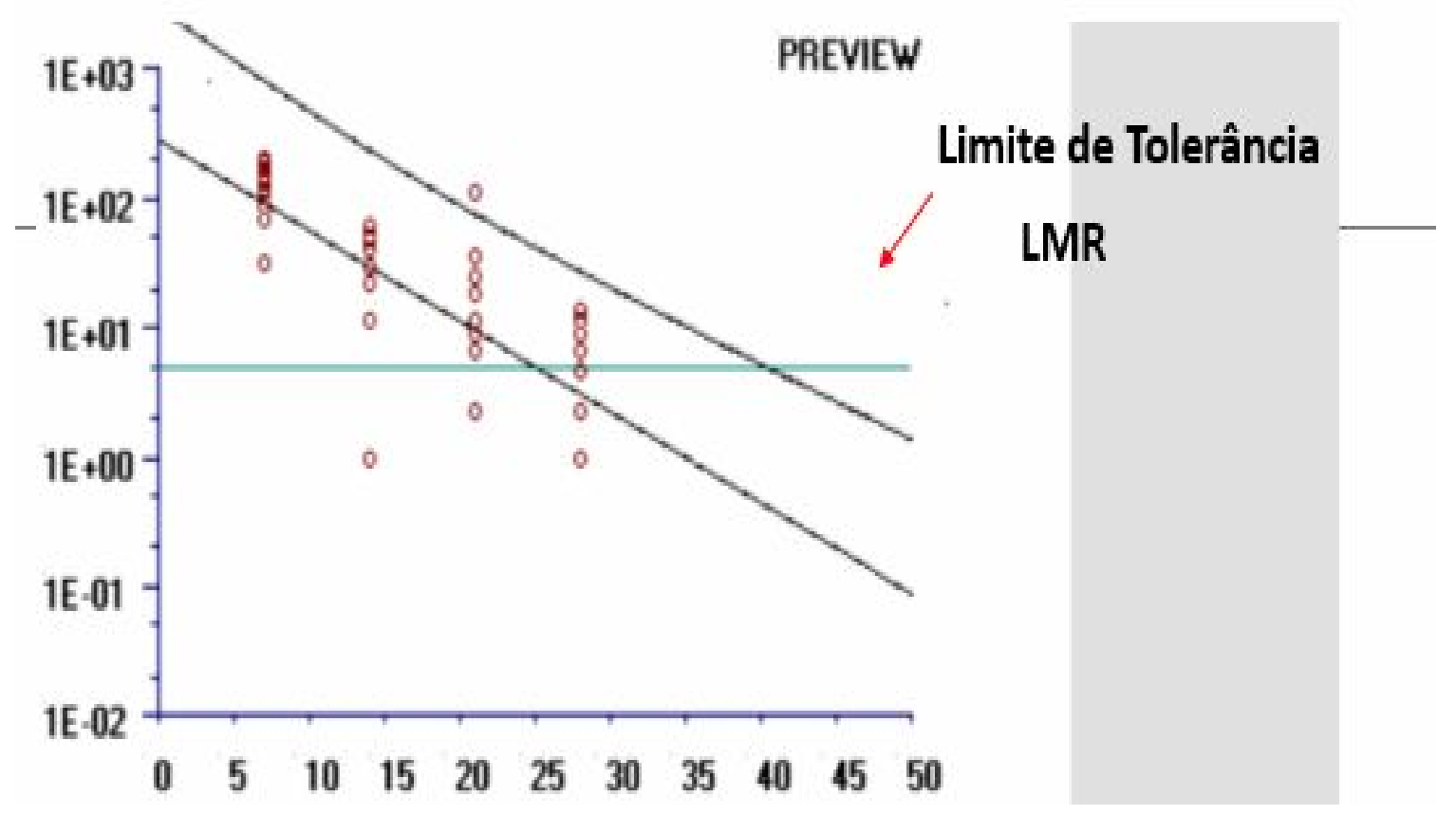

Fonte: Elaborado pelos autores (2021)

\section{4) Relatório Final do Estudo}

A etapa final, consiste na elaboração de um relatório que irá validar ou não o período de carência atestado na bula do PV, ou até determinar o período de carência a ser atestado em bula de novos PV. É nessa etapa em que os dados de cada análise e parâmetro avaliados durante todo o estudo será detalhada e justificada. A precisão dos dados é imprescindível para a garantia da rastreabilidade do produto e garantia da veracidade do estudo (CRMV, 2021).

O relatório em questão é compilado aos outros dados do ensaio clínico em forma de dossiê e é enviado ao patrocinador, o qual deve submeter ao MAPA, da mesma maneira que a empresa ou indivíduo responsável pela condução do estudo deve submeter esse arquivo ao site do CONCEA. Após a validação do estudo pelo CONCEA e aprovação do MAPA, o patrocinador consegue a licença para a comercialização do PV em questão (BRASIL, 2008; CRMV, 2021).

\section{CONSIDERAÇÕES FINAIS}

Devido à falta de um sistema de fiscalização minuciosa do gado no período pré-abate, vale destacar que a colaboração dos produtores de gado em relação aos 
tópicos abordados neste trabalho é fundamental para preservação da saúde pública brasileira e mundial, visto que o Brasil é um grande exportador de proteína animal.

Através do presente estudo foi possível compreender vários aspectos relevantes dentro do tema "Saúde Pública" significativos a todos os indivíduos e setores da sociedade. Desde a importância da realização de testes em animais (feitos sob supervisão e seguindo boas práticas) até ao entendimento da função e da importância da atuação do Médico Veterinário no cuidado da saúde humana agregando reconhecimento e oportunidade a essa classe profissional.

A explanação a respeito da gravidade do uso indiscriminado de antibióticos gera maior consciência a população, a qual respeitará e apoiar as campanhas e leis das autoridades médicas e sanitárias, além de possivelmente reivindicar quando os órgãos responsáveis não estiverem cumprindo seu papel.

\section{REFERÊNCIAS}

ANVISA - Agência Nacional de Vigilância Sanitária . Limites máximos de resíduos de medicamentos veterinários em alimentos de origem animal: documento base para discussão regulatória. Brasília: GEARE, 2018. Disponível em: http://antigo.anvisa.gov.br/documents/10181/5545276/Medicamentos+Veterin\%C3\% A1rios+-+Documento+base_discussao_28_DEZ_2018.pdf/b061f443-b558-4545$88 c 9-9246 b 184 \mathrm{e} 23 \mathrm{~b}$ ?version=1.0. Acesso em: 27 de set. de 2021.1

ARAÚJO, A. S.; SILVA, N. O.; LEAL, D. R. One health - A saúde única sob a percepção do estudante de medicina veterinária do Distrito Federal. Revista Ciência e Saúde Animal. Brasília, v. 2, n. 2, p. 9-18, jul. 2020. Disponível em: http://revistas.icesp.br/index.php/CSA/issue/view/203. Acesso em: 24 de set. de 2021.2

BRASIL. Ministério da Saúde. Conselho Nacional de Saúde (CNS). Resolução n. 196, de 1996. Aprova as diretrizes e normas regulamentadoras de pesquisas envolvendo seres humanos. Brasília: Ministério da Saúde, 1996. Disponível em: https://bvsms.saude.gov.br/bvs/saudelegis/cns/1996/res0196_10_10_1996.html.

Acesso em: 24 de set. de 2021.

BRASIL. Ministério da Saúde. Conselho Nacional de Saúde (CNS). Resolução n.o 287, de 1998. Relaciona categorias profissionais de saúde de nível superior para fins de atuação do CNS. Brasília: Ministério da Saúde, 1998. Disponível em: https://bvsms.saude.gov.br/bvs/saudelegis/cns/1998/res0287_08_10_1998.html. Acesso em: 29 de set. de 2021.

BRASIL. Ministério da Agricultura, Pecuária e Abastecimento (MAPA). Decreto $\mathbf{N}^{\circ}$ 5.053, de 2 de abril de 2004. Aprova o regulamento de fiscalização de produtos de uso veterinário e dos estabelecimentos que os fabriquem ou comerciem, e dá outras providências. Brasília: Ministério da Agricultura, 2004. Disponível em: http://www.planalto.gov.br/ccivil_03/_ato2004-2006/2004/decreto/d5053.htm. Acesso em: 24 de set. de 2021.

BRASIL. Câmara dos Deputados. Projeto de Lei 6492/2006, de 17 de janeiro de 2006. Dispõe sobre a dispensação de medicamentos contendo antimicrobianos. Brasília: Câmara dos Deputados, 2006. Disponível em: 
https://www.camara.leg.br/proposicoesWeb/prop_mostrarintegra?codteor=367837\&fil ename $=P L+6492 / 2006$. Acesso em: 23 de set. de 2021.

BRASIL. Presidência da República. Lei $\mathrm{n}^{\circ}$ 11.794,de 08 de outubro de 2008. Regulamenta o inciso VII do parágrafo $1^{\circ}$ do artigo 225 da Constituição Federal, estabelecendo procedimentos para o uso científico de animais; revoga a lei $n^{\circ} 6.638$, de 8 de maio de 1979; e dá outras providências. Brasília: Casa Civil, 2008. Disponível em: http://www.planalto.gov.br/ccivil_03/_ato20072010/2008/lei/l11794.htm. Acesso em: 01 de out. de 2021.

BRASIL. Ministério da Agricultura, Pecuária e Abastecimento (MAPA). Guia I: Boas Práticas Clínicas (BPC). Brasília: CPV, 2009. Disponível em: https://www.invitare.com.br/arq/legislacao/veterinaria/Manual-Boas-Pr-ticas-Cl-nicasMAPA.pdf. Acesso em: 27 de set. de 2021.

BRASIL. Ministério da Agricultura, Pecuária e Abastecimento (MAPA). Instrução Normativa № 51, de 3 de agosto de 2020. Estabelece os critérios e procedimentos para a fabricação, fracionamento, importação e comercialização dos produtos dispensados de registro para uso na alimentação animal. Brasília: Ministério da Agricultura, 2020. Disponível em: https://in.gov.br/web/dou/-/instrucao-normativa-n51-de-3-de-agosto-de-2020-270471891. Acesso em: 27 de set. de 2021.

BRASIL. Ministério da Agricultura, Pecuária e Abastecimento (MAPA). Programa de vigilância e monitoramento da resistência aos antimicrobianos no âmbito da agropecuária (2019-2022). Brasília: MAPA, 2021a. Disponível em: https://www.gov.br/agricultura/pt-br/assuntos/insumos-agropecuarios/insumospecuarios/resistencia-aos-antimicrobianos/pan-bragro/ProgramadeVigilnciaeMonitoramentoAMR_2021.pdf. Acesso em: 24 de set. de 2021.

BRASIL. Ministério da Agricultura, Pecuária e Abastecimento (MAPA). Regra dos cinco "somentes". Brasília: MAPA, 2021b. Disponível em: https://www.gov.br/agricultura/pt-br/assuntos/insumos-agropecuarios/insumospecuarios/resistencia-aos-antimicrobianos/regra-dos-cinco-201csomentes201d. Acesso em: 24 de set. de 2021.

CEARÁ. Secretaria de Saúde do Estado. Uso racional de antibióticos. Grupo de Prevenção do Uso Racional de Medicamentos (GPUIM). Fortaleza: Secretária da Saúde, 2021. Disponível em: https://www.saude.ce.gov.br/wpcontent/uploads/sites/9/2021/04/Uso_racional_de_antibioticos.pdf. Acesso em: $01 \mathrm{de}$ out. de 2021.

CFMV - Conselho Federal de Medicina Veterinária. Saúde única. Brasília: CFMV, 2020. Disponível em: https://www.cfmv.gov.br/saudeunica/comunicacao/2018/10/09/. Acesso em: 01 de out. de 2021.

CFMV - Conselho Federal de Medicina Veterinária. Guia de boas práticas clínicas para avaliação de produtos veterinários. São Paulo: CRMV, 2021. Disponível em: https://www.sbppc.org.br/downloads/guias-de-boas-praticas-clinicas.pdf. Acesso em: 01 de out. de 2021. 
EMBRAPA - Empresa Brasileira de Pesquisa Agropecuária. Mapas e infográficos: participação da produção brasileira no mundo-2019. Concórdia: Central de Inteligência de Aves e Suínos, 2019. Disponível em: https://www.embrapa.br/documents/1355242/0/CIAS+-+2019+-

+Participa\%C3\%A7\%C3\%A30+da+produ\%C3\%A7\%C3\%A3o+brasileira+no+mundo -BRA.png. Acesso em: 01 de out. de 2021.

EMBRAPA - Empresa Brasileira de Pesquisa Agropecuária. O agro no Brasil e no mundo: uma síntese do período de 2000 a 2020. Brasília: SIRE, 2021. Disponível em:

https://www.embrapa.br/documents/10180/62618376/O+AGRO+NO+BRASIL+E+NO +MUNDO.pdf/41e20155-5cd9-f4ad-7119-945e147396cb. Acesso em: 03 de out. de 2021.

WHO - Food and Agriculture Organization of the United Nations (FAO); World Health Organization. Codex 2019: the year of food safety. Roma: Codex Alimentarius Commission, 2019a. Disponível em: https://www.fao.org/3/ca5180en/CA5180EN.pdf. Acesso em: 03 de out. de 2021.

WHO - Food and Agriculture Organization of the United Nations (FAO); World Health Organization. Codex strategic plan 2020-2025. Roma: Codex Alimentarius Commission, 2019b. Disponível em: https://www.fao.org/3/ca5645en/CA5645EN.pdf. Acesso em: 03 de out. de 2021.

WHO - Food and Agriculture Organization of the United Nations (FAO); World Health Organization. Codex strategic plan 2014-2019. Implementation Report. Roma: Codex Alimentarius Commission, 2021. DOI 10.4060/cb2927en. Disponível em: https://doi.org/10.4060/cb2927en. Acesso em: 04 de out. de 2021.

GONZALES, E.; MELLO, H. H. C.; CAFÉ, M. B. Uso de antibióticos promotores de crescimento na alimentação e produção animal. Revista UFG, [S. I.], v. 13, n. 13, 2017. Disponível em: https://www.revistas.ufg.br/revistaufg/article/view/48453. Acesso em: 04 de out. de 2021.

GUIMARÃES, D. O.; MOMESSO, L. S.; PUPO, M. T. Antibióticos: importância terapêutica e perspectivas para a descoberta e desenvolvimento de novos agentes. Química Nova [online], v. 33, n. 3, p. 667-679, 2010. DOI 10.1590/S010040422010000300035. Disponível em: https://doi.org/10.1590/S010040422010000300035. Acesso em: 05 de out. de 2021.

$\mathrm{VICH}$ - International cooperation on harmonisation of technical requirements for registration of veterinary medicinal products. VICH topic GL48: Studies to evaluate the metabolism and residue kinetics of veterinary drugs in foodproducing animals: marker residue depletion studies to establish product withdrawal periods. Londres: $\mathrm{VICH}$, 2015. Disponível em: https://www.ema.europa.eu/en/documents/scientificguideline/vich-gl48-studies-evaluate-metabolism-residue-kinetics-veterinary-drugsfood-producing-animals_en.pdf. Acesso em: 05 de out. de 2021. 
$\mathrm{VICH}$ - International cooperation on harmonisation of technical requirements for registration of veterinary medicinal products. Guideline on good clinical practices. Londres: $\mathrm{VICH}, 2000$. Disponível em: https://www.vichsec.org/en/guidelines.html. Acesso em: 05 de out. de 2021.

LENHARO, M. No Brasil, $\mathbf{4 1} \%$ da população é contra testes com animais, revela pesquisa.G1 Globo, São Paulo, 12 junho 2014. Ciência e Saúde. Disponível em: http://g1.globo.com/ciencia-e-saude/noticia/2014/12/no-brasil-41-da-populacao-econtra-testes-com-animais-revela-pesquisa.html. Acesso em: 05 de out. de 2021.

MOTA, R. A.; SILVA, K. P. C.; FREITAS, M. F. L.; PORTO, W. J. N.; SILVA, L. B. G. Utilização indiscriminada de antimicrobianos e sua contribuição a multirresitência bacteriana.Brazilian Journal of Veterinary Research and Animal Science, São Paulo, v. 42, n. 6, p. 465-470, 2005. DOI 10.11606/issn.16784456.bjvras.2005.26406. Disponível em: https://doi.org/10.11606/issn.16784456.bjvras.2005.26406. Acesso em: 06 de out. de 2021.

NC3Rs - National Centre for the replacent, Refinement \& reduction of animals in research. The 3Rs. Londres: NC3Rs, 2021. Disponível em: https://nc3rs.org.uk/the3rs.

ONU - Organização das nações unidas. Sumário para os formuladores de políticas. Genebra: $\quad 2020.2$ Disponível em: https://www.ipcc.ch/site/assets/uploads/2021/03/ar4-wg1-spm.pdf. Acesso em: 26 de set. de 2021.

OMS- Organização Mundial da Saúde. A crescente ameaça da resistência antimicrobiana. Genebra: OMS, 2012. Disponível em: https://www.saude.rj.gov.br/comum/code/MostrarArquivo.php?C=OTgzMw\%2C\%2C. Acesso em: 23 de set. de 2021.

OPAS - Organização Pan-americana da Saúde. Resistência antimicrobiana. Brasília: OPAS, 2021. Disponível em: https://www.paho.org/pt/topicos/resistenciaantimicrobiana. Acesso em: 23 de set. de 2021.

SNUSTAD, P. Fundamentos da genética. 7. ed. Rio de Janeiro: Guanabara Koogan, 2017.

TAVARES, W. Antibióticos e quimioterápicos para o clínico. 3. ed. São Paulo: Atheneu, 2014.

WERTHEIN, J. A,; sociedade da informação e seus desafios. Ciência da Informação [online], v. 29, n. 2, p. 71-77, 2000. DOI 10.1590/S010019652000000200009. Disponível em: https://doi.org/10.1590/S010019652000000200009. Acesso em: 28 de set. de 2021.

WHO - World Health Organization. New report calls for urgent action to avert antimicrobial resistance crisis. Washington: WHO, 2019. Disponível em: https://www.who.int/news/item/29-04-2019-new-report-calls-for-urgent-action-toavert-antimicrobial-resistance-crisis. Acesso em: 23 de set. de 2021. 
WHO - World Health Organization.. Food safety. Washington: WHO, 2020. Disponível em: https://www.who.int/news-room/fact-sheets/detail/food-safety. Acesso em: 23 de set. de 2021.

OIE - World Organization for animal Health . Controlling global health risks more effectively. Paris: OIE, 2019. Disponível em: https://www.oie.int/en/what-wedo/global-initiatives/one-health/. Acesso em: 07 de out. de 2021. 